\title{
THOSE WHO CAN DO, TEACH: THE IMPORTANCE OF BRIDGING THE DELIVERY AND APPLICATION OF LEARNING IN TERTIARY EDUCATION
}

\author{
Kawtar Tani
}

\section{INTRODUCTION}

Overlap in the raison d'être of universities and polytechnics is likely increasing. While, historically, there was greater emphasis in polytechnic institutions on providing training for employment in the workplace, there is much less of a dichotomy today. At least in Germany, Voss and Gruber's (2006) survey of student expectations supports such a shift: "students are mainly concerned about vocational aspects of their studies and are less interested in their subject" (p. 234).

In many fields, the expectation that teaching staff (for example, lecturers, tutors and teaching assistants) will be up-to-date in their areas will seldom have been put to the test. Indeed, a lecturer, whether having assistant or full status, may have been working in a higher education environment for many years and have vanishingly little currency in the area that they teach, with respect to how it is operationalised in the 'real world.' While in some areas current real-world experience is unlikely to be an issue (for example, philosophy and politics majors), in other areas it will almost certainly be highly relevant (nursing, IT, accountancy).

George Bernard Shaw is credited with saying, "He who can, does. He who cannot, teaches," a quip which has frequently been repeated in the context of education. The implication is that teachers are not on a par with those who are practitioners in the field; that the teaching profession is full of those who have failed outside the world of academia; and that students are learning from teachers who may not possess the capability to help them succeed outside of the classroom. While such implications may be too extreme, such truisms often contain a kernel of the truth. Some believe that the ability to teach is completely separate from the ability to do. For example, having the ability to coach a team to succeed is different from being a successful player. Good teachers are not necessarily good performers, but they may produce good performers.

Many concur with George Bernard Shaw's witticism and argue that it is impossible to understand how to do something, but be unable to do it, and there is some truth in this. For example, in order to teach a musical instrument, the teacher has to be able to play the instrument themselves. Or, in order to be able to teach medicine, the teacher has to be a practitioner of medicine. However, being able to transfer the ability to do something to the realm of knowledge is different from being able to do something well, or to teach well.

There is a perception that educators in the majority of disciplines in tertiary education focus on the theories and abstract principles of an industry, without ever having implemented them themselves. It is possible that the best educators in tertiary education are those with experience and accomplishment in their fields. According to Charles Mayo, one of the founders of the internationally renowned Mayo Clinic, who was considered to be a surgical wonder of his time and an inspirational teacher, a doctor must always be a student in order to be a teacher of medicine (Naini, 2006). 


\section{THE TRIANGLE OF THE MODERN EDUCATOR}

My proposed model (Figure I) is built on the argument that quality teaching in tertiary education organisations is not just about pedagogical and research skills, but also about the professional skills of the educator. Well-rounded educators are likely to have these traits, as well as the willingness to enhance their abilities as needed in order to address the needs of their learners. According to Boice (1992), the key professional qualities involved include technical competence, disciplinary competence and knowledge about career advancement.

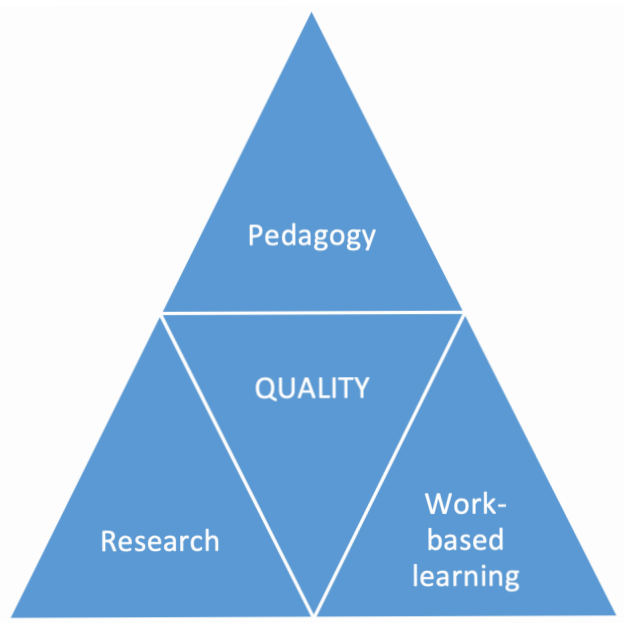

Figure I. The triangle of the modern educator. Source: Author.

The model (Figure I) is a triangle which emphasises that the three primary components of quality in tertiary education are: i) pedagogy - a deep knowledge of topics and the ability to deliver these well; ii) research possessing an enquiring and analytical mind and the skills to enhance pedagogy; and iii) work-based learning professional and practical skills to support the enhancement of pedagogy.

The proposed model highlights that the key characteristic of a quality educator is their ability to 'do' as well as 'teach,' where teaching means delivering learning. Thus, developing the components of the triangle could empower educators to give quality professional and pedagogical guidance to meet the expectations of the new generation. Deficiency in any of the components of the triangle could result in a compromise in quality. For example, a person who has been mostly 'doing' may not be able to explain why and how, compared with an educator whose main skills lie in disseminating the details of a subject with the support of the relevant literature.

Tertiary education organisations differ in their emphasis on the practical skills of their educators. While mainstream higher education institutions might emphasise the need for research skills, tertiary education organisations put more weight on the ability to deliver learning and the ability to demonstrate possession of practical skills.

In the institution where I am employed, a tertiary education organisation, demonstrating practical skills is one of the most highly recommended attributes for a new educator. However, maintaining these practical skills is not an easy task, given the high teaching workloads of staff. As a result, most educators focus on pedagogical skills. In saying that, the institution is not opposed to professional development, sabbaticals and opportunities to improve relationships with industry. For example, when I sought to reduce my teaching hours in order to conduct work in industry, my employer recognised the benefits of going back to industry after four years of teaching. These benefits include maintaining the currency of my technical skills, building relationships with stakeholders in industry (which has the further potential benefit of creating work placement opportunities for my students), and ensuring 
that the content of my courses aligns with current industry demands. Indeed, this exercise resulted in creating opportunities for work-based learning for our students, exposed me to current practices in industry, and equipped me with recent case studies that I used in the classroom to support delivery of learning.

\section{DOES WORK-BASED LEARNING MATTER?}

Some of us, looking back over our higher or tertiary education, can attribute our likes and dislikes of particular topics to one or more lecturers. Indeed, correlational evidence indicates a relationship between academic success and liking a particular lecturer (for example, Montalvo et al., 2007), who may have instilled in us the desire to pursue a particular career path. Most tertiary education organisations invest in a variety of ways to deliver programmes and develop the pedagogical techniques of educators. Arguably, however, neither pedagogical techniques, personality traits nor likeability ensure that academics possess the professional skills that students need to learn (Chan, 20I8).

Many tertiary education organisations, especially those offering applied programmes, have compulsory courses where students in their final year of study undertake a work placement in industry to get some 'hands-on' experience related to their programmes of study, such as project work or internships. This is evidence that tertiary education organisations see the value to students of gaining work experience, and their success in the work-based course component indicates that they are capable of joining the 'real-life' world. If this is the case, then should tertiary education organisations place an equal importance on the practical skills of their educators? Work-based learning may "assure academics of their professional immortality by attending to the needs of the next generation" (Hayes, 2005, p. 445).

\section{PROFESSIONAL DEVELOPMENT OF EDUCATORS IN TERTIARY EDUCATION}

Most, if not all, higher education institutes are expected to be involved in research. In most disciplines taught in higher education institutions, collaboration between industry and academia exists at the research level, with senior academics being more involved, and more expected to get involved, in research activities. This situation is no different for tertiary education organisations; the New Zealand Qualifications Authority (NZQA) mandates that all teaching staff of degree-level programmes and postgraduate programmes be research-active (NZQA, 2020). More recently, there has been an incentive for tertiary education organisations delivering degree programmes to also be actively involved in research (for example, through the Performance-Based Research Fund (PBRF) funding mechanism). As a result, it is less common for educators in these organisations to look for work-based learning opportunities to gain hands-on knowledge of the modern workplace, and both the specific competencies and generic skills that are in demands in their sectors (Chan, 2018). Rather, most of their professional lives are spent within their educational institutions. Indeed, the professional development programmes and sabbaticals offered to educators in tertiary education organisations are mostly about developing their research and teaching skills. It is proposed that work-based learning should be a compulsory part of the professional development of educators in tertiary education, even those whose disciplines do not map closely to a particular professional sector.

Professional development programmes outside the framework of the traditional teaching and research model may provide an alternative opportunity for developing professional and practical skills that could benefit students. During recruitment, potential educators in tertiary education organisations could be asked about the specific area of expertise in which they have practical work experience, and how they believe they can maintain and enhance that experience to benefit their students. However, this approach can only be successful if educators are willing to devote time and energy to develop their work-based learning skills, and when tertiary education organisations are willing to empower new and continuing educators by supporting their professional growth and renewal (Boice, 1992). Indeed, Chan (2018) maintains that potential educators should undergo a year-long work-based learning program before they start teaching. Chan also maintains that as part of educators' professional development and career advancement, they should return to work in industry every three to five years. 


\section{LIMITATIONS}

There are a number of limitations associated with the implementation of this model. While tertiary education organisations might not be opposed to the idea of educators' request for work-based learning on a temporary basis, it will always be difficult to cover the workload of educators while they are working in industry. However, some tertiary education organisations have adopted teaching and non-teaching semesters, presenting a valuable opportunity for work-based learning to be achieved. In the absence of such an approach, effective planning and organisation of staff workloads might overcome this limitation.

Another possible limitation might be the lack of commitment on the part of both staff and employers to implement the model. Not all would see the benefits of the proposed model. Educators, especially those who have been teaching for a long period of time, might be reluctant to gain new practical skills. Similarly, employers might lack the resources to support the implementation of the model and the focus would remain on the immediate needs of the institution, which are often related to teaching and delivery of courses.

\section{CONCLUSION}

Every tertiary education organisation is in need of educators having abilities in both the delivery and application of learning. Educators' credibility lies in their ability to break down their subject matter for their learners, their ability to explain complex problems in ways that their learners can understand, and their ability to get very specific about details, which often comes from applied experience.

Educators need to be up-to-date with advancements in professional practice and pedagogy, so that the future workforce is equipped with the right skills to find its proper place in this dynamic environment.

Kawtar Tani is a senior lecturer and a programme leader at the School of Business and ICT at UCOL, Palmerston North. Kawtar has extensive experience in the business and IT environments, and is actively involved in the continuous improvement of learning and delivery of programmes in tertiary education.

(10 https://orcid.org/0000-0003-1031-9536

\section{REFERENCES}

Boice, R. (1992). The new faculty member. Jossey-Bass.

Chan, C. K. Y. (Feb 22, 20 I8). Work experience should be a job requirement for academics. https://world.edu/work-experience-jobrequirement-academics/

Hayes, E. F. (2005). Approaches to mentoring: How to mentor and be mentored. Journal of the American Academy of Nurse Practitioners, I7(II), 442-445.

Montalvo, G., Mansfield, E., \& Miller, R. (2007). Liking or disliking the teacher: Student motivation, engagement and achievement. Evaluation \& Research in Education, 20(3), 144-158.

Naini, F. B. (2006). So, those who can't do it, teach it? BMJ, 332(7535), 219.

NZQA. (2002). Guidelines for approving and maintaining degrees and related qualifications. https://www.nzqa.govt.nz/assets/ Providers-and-partners/Registration-and-accreditation/Degree-approval-and-monitoring/guidelines-degree-and-relatedquals.pdf.

Voss, R., \& Gruber, T. (2006). The desired teaching qualities of lecturers in higher education: A means end analysis. Quality Assurance in Education, 14(3), 217-242. 